\title{
IMPLEMENTING SUSTAINABLE ERGONOMICS FOR POWER-LOOM TEXTILE WORKERS
}

\author{
SOMNATH KOLGIRI' ${ }^{\text {, RAHUL HIREMATH² }}$
}

${ }^{1}$ Mechanical Department, Walchand Institute of Technology, Solapur University, Solapur, Maharashtra, India, ${ }^{2}$ SCMHRD, Pune Email: sgkolgiri@gmail.com

Received: 15 Aug 2017 Revised and Accepted: 08 May 2018

\begin{abstract}
Objective: This ergonomic study focuses on identifying and understanding the occupational health and safety risk aspects of power-loom industry workers from Solapur City, Maharashtra, India.
\end{abstract}

Methods: The samples of 540 workers were assessed for their general physique, muscle tone (MT), a lung condition, and eyesight (ES) using different techniques. The body mass index (BMI) was used to asses normal physique. The Snellen chart was used to check normal eyesight. A peak flow meter was used to determine lung condition.

Result: In this study, it was found that most of the workers were influenced by respiratory issues, increase in muscle tone, eye issues and musculoskeletal issues. The subjects were compared with controls. Linear regression analysis shows (OR: 0.356; 95\% CI: 0.287-0.426) p<0.05*.

Conclusion: Based on these outcomes; it strongly emphasized the need for policies for successful implementation of health safety program. Therefore, to improve the health of these workers the suggestions and recommendations were presented in accordance with the ergonomics principle and existing labor laws.

Keywords: Ergonomics, Health and safety, Solapur city, Power-loom

(C) 2018 The Authors. Published by Innovare Academic Sciences Pvt Ltd. This is an open access article under the CC BY license (http://creativecommons.org/licenses/by/4.0/) DOI: http://dx.doi.org/10.22159/ijpps.2018v10i6.26213

\section{INTRODUCTION}

The textile sector in India plays an important role in the country's economy and provides employment to many people in peri-urban and rural areas. Apart from providing one of the basic necessities of life, i.e. clothing, the textile industry contributes about $14 \%$ to the country's industrial output. The sector employs nearly 35 million people and after agriculture, is the second-highest employer in the country [1]. This sector has wide spectrum of industries ranging from small-scale units that use traditional manufacturing process, to large integrated mills using modern machineries and equipment. It can be broadly classified into two categories, the organized mill and the unorganized decentralized sector. The organized sector of the textile industry having, the spinning, weaving and processing facilities are carried out in one roof. The yarn is mostly produced in the spinning mills, fabrics are produced in three major segments the power loom, handloom and hosiery., Out of three segments, the power loom plays a vital role in Indian textile industry and providing the employment opportunities to 4.86 million people of the country in 2009 [2, 3]. The state of Maharashtra in India with an estimated investment in 2012 of United State Dollar (US\$) 224 million on various textile projects is the biggest contributor to India's textiles market [3]. The prominent textile clusters in the state are Kolhapur, Nasik, Solapur and Thane. Solapur city is an important district head quarter in western Maharashtra located at $17.6599^{\circ} \mathrm{N}, 75.9064^{\circ} \mathrm{E}$, and is famous for its power-loom industry (Chaddar and Towel), and Beedi making Industries [4].

There are approximately 3500 units in this cluster, which are engaged in manufacturing of textile products such as towels, napkins and bed-sheets. The textile clusters are spread across different parts of the city and involves the use of 25,000 power looms today and employing about 100,000 workers [5,6]. The operations involved in typical textile plant are fiber production, spinning, twisting, textile yarn production, weaving, knitting, dyeing and finishing. Thus the manufacturing processes convert raw materials into finished goods with entire process based on systematic function allocation to humans and machines. The human interference is essential during every operation mentioned.
Further, in the processing of textiles, the industry uses a number of dyes, chemicals, auxiliary chemicals and sizing materials. Apart from occasionally occurring serious accidents, the textile industry is generally seen as a safe place to work in comparison with other industries. The main health risks in this industry do not occur from immediate, potentially mortal hazards; instead, the risks that textile workers face come from more slight hazards whose effect accumulates over time. These injuries regularly start as minor aches and pains, but can build up into disabling injuries that involve our activities of daily living such as laundry and even the ability to pick up our children [7]. There is evidence from a few researches in India about health risks to industry workers. Suryakar et al. [8] conducted experiments to assess exposure effects of cotton dust on oxidant and antioxidant in the spinning section of Misr Helan Spinning and Weaving Industry, Helwan, which may induce, related health hazards such as oxidative stress and immunoglobulin levels (IgG and IgM). Another article by Agnihotram [9] provided a review of existing evidence from community based epidemiological studies and addressed the growing need for evidence-based occupational health research in India. Knutsson [10] focuses on major disease related to shift work such as sleep disorders and risk of accidents. The effects of shift work on physiological function through disruption of circadian rhythms are well described. Knutsson [10] also provides a model to summarize possible mechanisms of disease in shift workers. Metgud et al. [11] conducted an observational cross-sectional study of a sample of 100 women workers with respect to their cardio-respiratory and musculoskeletal profile before, during and at the end of the work. Sant et al. [12] have studied the adverse effect of smoke/flue on lung functions of glass factory workers of Firozabad district. Müezzino [13], Spiro and Stigliani [14] and Hendrickson et al. [15] have reported the adverse health impacts of textile effluents. Gupta et al. [16] have studied 130 male textile mill workers from the different sections of a textile mill their body mass index (BMI) and respiratory functions were evaluated. This study shows with short-term exposure to cotton dust, may also present with respiratory alterations which may increase with long-term exposure. Ayesha Anjum et al. [17] reported the health concerns among workers in weaving industry due to exposure to 
toxic chemicals, occupational health problems of workers involved in hand made carpets. They also mentioned, the workers were subjected to health problems like skeletal deformities, ergonomic, eyesight and several others. Further, the impact on the health of the different exposures varies across different strata in the community, like age groups, social groups, gender, occupations, education and other characteristics [17].

On lines similar with literature, the present study tries to assess the occupational health problems faced by the power-loom industry workers from Solapur, Maharashtra, India. Further, to reduce these health hazards the recommendations in accordance with the ergonomics principle and available labor laws were prescribed.

\section{MATERIALS AND METHODS}

The health problems related to the workers in the power-loom industry were assessed with the help of field survey. During this survey, semi-structured interviews of unit owners and workers in various power-loom industries were conducted with the help of a checklist. The effect of process on raw materials used in this mill, were assessed by the operational performance indicator under, environmental performance indicator (EPI), review of existing CETP units (Centralized Effluent Treatment Plant recently established) and present health status of workers and their working conditions were analyzed. The study covered both small scale and medium scale units. At the first stage, out of 49 power-loom units from the city a total of 15 powers-loom industries were selected by random sampling technique. This is approximately $31 \%$ of the entire population. The field survey of the power-loom industry has been done during December 2015 to December 2016. In the second stage, workers were selected from these power-loom mills, for the selective purpose of respondents a complete list of permanent workers between the ages of 21 to 60 which having the minimum 3 y work experience was proportionally selected from all the 15 power-loom industries. A sample of 540 workers (consented to be interviewed) from power-loom industries participated and they were assessed on various measurements.

The monitoring equipment's and parameters for measuring occupational health status are detailed below

\section{Weight and height}

The body mass index (BMI) is a heuristic proxy for human body fat based on an individual's weight and height. The BMI is a function of patterns of food consumption, associated living and working conditions, the nature and duration of physical work $[18,22]$.

\section{Hand grip meter}

The test measures the maximum isometric strength of the hand and forearm muscles. This test is typically used as a general test of strength. The strength also depends upon various activities like daily food intake, working hours, and pattern of work [19].

\section{Peak flow meter}

A peak flow meter is a handy, economical, handheld device used to measure how air flows from the lungs in one "quick impact" [20]. The peak flow measurement of $350 \mathrm{l} / \mathrm{min}$ is considered to be normal for adults, while $200 \mathrm{l} / \mathrm{min}$ indicates a condition of chronic bronchitis and, therefore, major lung damage.

\section{Eye testing}

The Snellen chart is used by eye care professionals and others to measure visual acuity. There are several lines of black letters printed on the chart. The first line consists of very large letters or symbols, and subsequent rows have increased letters or symbols decreasing in size. If the smallest row can be read accurately, it indicates that the person has good eyesight [21].

The data obtained by survey of workers in the light of above parameters were analyzed to quantify the assessment of probable health problems. The results obtained from this study are described in the following paragraphs.

\section{Statistical methods}

Data were expressed as the mean \pm SD. Student's $t$ test was performed to assess differences between two means. Statistical analysis was performed using SP statistical software for research studies. Differences in means between groups were tested using independent-sample t-tests. $\mathrm{p}<0.05$ was considered as statistically significant. A linear regression method was used to correlate workers with the controls.

\section{RESULTS AND DISCUSSION}

\section{Health and safety indicators}

The industries that were surveyed, the team was able to interview and measure selected health parameters of 540 workers. To aid comparison of the occupational health status, these workers were divided into two categories depending on the number of years of engagement in the current unit: 372 of them had been with the units for up to $5 \mathrm{y}$, while 168 had worked for more than $5 \mathrm{y}$. Table 1 shows the no. of workers engaged in various processes in our sample.

Table 1: It shows the demographic distribution of subjects

\begin{tabular}{|c|c|c|c|c|c|c|}
\hline \multirow[t]{3}{*}{ Textile Processes } & \multirow[t]{3}{*}{ Years worked in present unit } & \multicolumn{4}{|c|}{ Number of Workers } & \multirow[t]{3}{*}{ Total number of workers } \\
\hline & & \multicolumn{2}{|c|}{ Male } & \multicolumn{2}{|l|}{ Female } & \\
\hline & & $\begin{array}{l}\text { Age group } \\
20-40 \mathrm{y}\end{array}$ & $\begin{array}{l}\text { Age group } \\
40-60 \mathrm{y}\end{array}$ & $\begin{array}{l}\text { Age group } \\
20-40 y\end{array}$ & $\begin{array}{l}\text { Age group } \\
40-60 y\end{array}$ & \\
\hline Thread Formation & $0-5$ & 16 & 20 & 9 & 13 & 60 \\
\hline Spinning & $>5$ & 22 & 29 & 15 & 18 & 84 \\
\hline Weaving & $0-5$ & 23 & 32 & 17 & 20 & 90 \\
\hline Knitting & $>5$ & 25 & 34 & 18 & 21 & 96 \\
\hline Bleaching & $0-5$ & 18 & 24 & 14 & 16 & 72 \\
\hline Dyeing & $>5$ & 14 & 19 & 10 & 11 & 54 \\
\hline Printing & $0-5$ & 12 & 15 & 10 & 11 & 48 \\
\hline Finishing & $>5$ & 9 & 12 & 7 & 8 & 36 \\
\hline Total & NA & 139 & 182 & 102 & 117 & 540 \\
\hline Control & NA & 140 & 180 & 100 & 120 & 540 \\
\hline
\end{tabular}

Data were obtained by direct interview with respect to work experience level and age of worker.

\section{Body mass index (BMI)}

The BMI of the workers as showed in table 2. In (20-40 y) age group, $63 \%$ of power loom male workers have shown abnormal body mass index while $66 \%$ female workers were having shown abnormal BMI. In (40-60 y) age group, 75\% male workers have shown abnormal BMI while $79 \%$ female workers have shown abnormal BMI. The abnormal BMI percentages in male and female controls were less in both age groups. We compared BMI of power loom workers with controls in both age groups. The linear regression analysis is $(0.286$; $95 \% \mathrm{CI}$ : $0.187-0.226)$ $\mathrm{p}<0.05^{*}$. 
Table 2: It shows characteristic of subjects (Age, BMI, PFT, FGM and ES)

\begin{tabular}{|c|c|c|c|c|c|c|c|c|c|c|c|c|c|c|c|c|}
\hline \multirow[t]{3}{*}{ Characteristics } & \multicolumn{16}{|c|}{$\begin{array}{l}\text { Power-loom workers } \\
\text { Controls }\end{array}$} \\
\hline & \multicolumn{4}{|c|}{ Male } & \multicolumn{4}{|c|}{ Female } & \multicolumn{4}{|c|}{ Male } & \multicolumn{4}{|c|}{ Female } \\
\hline & 20-4 & & $40-6$ & & $20-$ & & $40-6$ & & 20-4 & & $40-6$ & & $20-4$ & & 40 - & \\
\hline Age in years (mean) & 30 & & 45 & & 29 & & 42 & & 30 & & 45 & & 28 & & 41 & \\
\hline Percentage & $\mathrm{N}^{\mathrm{a}}$ & $\mathrm{AN}^{\mathrm{b}}$ & $\mathrm{N}$ & AN & $\mathrm{N}$ & AN & $\mathrm{N}$ & AN & $\mathrm{N}$ & AN & $\mathrm{N}$ & AN & $\mathrm{N}$ & $\mathrm{AN}$ & $\mathrm{N}$ & AN \\
\hline $\begin{array}{l}\text { Body Mass Index } \\
\text { (BMI) }\end{array}$ & 37 & 63 & 32 & 68 & 34 & 66 & 31 & 79 & 76 & 24 & 67 & 33 & 69 & 31 & 59 & 41 \\
\hline Pulmonary Function Test & 37 & 63 & 25 & 75 & 43 & 57 & 30 & 70 & 80 & 20 & 61 & 39 & 71 & 29 & 57 & 43 \\
\hline Hand Grip Meter & 45 & 55 & 27 & 73 & 46 & 54 & 33 & 77 & 83 & 17 & 70 & 30 & 84 & 16 & 63 & 37 \\
\hline Eye Sight & 40 & 60 & 23 & 77 & 47 & 53 & 27 & 73 & 72 & 28 & 62 & 38 & 87 & 13 & 70 & 30 \\
\hline
\end{tabular}

aN: Normal, bAN: Abnormal.

Table 3: It shows abnormal percentage of BMI, PFT, HGM, and ES in subjects

\begin{tabular}{llll}
\hline Characteristics $^{\mathbf{a}}$ & \multicolumn{2}{c}{ Cowtrols } & \multicolumn{2}{c}{$\mathbf{2 0 - 4 0}$ y } \\
\cline { 2 - 4 } & $\mathbf{2 0 - 4 0} \mathbf{y}$ & $\mathbf{4 0 - 6 0} \mathbf{y}$ & $27.5 \pm 2.1$ \\
\hline Body Mass Index (BMI) & $64.5^{*} \pm 5.1$ & $73.5^{*} \pm 7.3$ & $37 \pm 3.2$ \\
Pulmonary Function Test & $60^{*} \pm 2.8$ & $72.5^{*} \pm 3.5$ & $24.5 \pm 1.2$ \\
Hand Grip Meter & $54.5^{*} \pm 3.6$ & $75^{*} \pm 5.1$ & $16.5 \pm 0.8$ \\
Eye Sight & $56.5^{*} \pm 2.4$ & $75^{*} \pm 4.7$ & $20.5 \pm 2.1$ \\
\hline
\end{tabular}

${ }^{*} \mathrm{P}$ value 0.05 is significant when compared to controls. ${ }^{a}$ mean $\pm S D, n=4$.

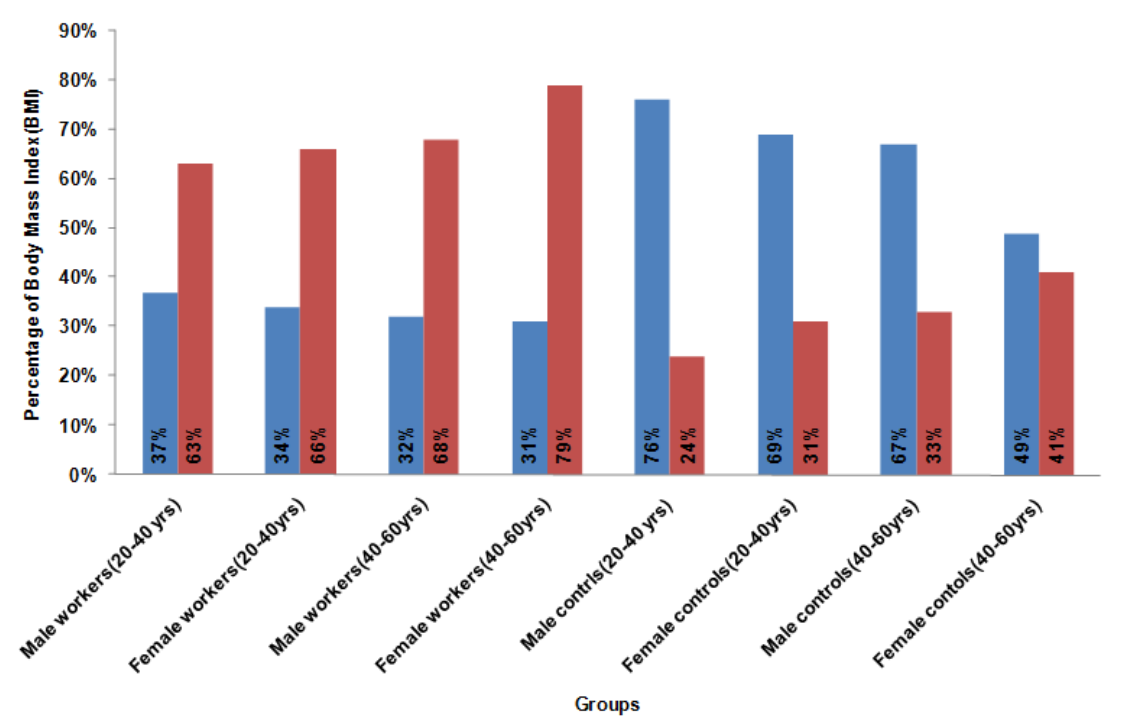

Fig. 1: Bar diagram showing percentage of body mass index (BMI)

\section{Pulmonary function test (PFT) and pulmonary health}

The PFT of the workers was as shown in table 2. In (20-40 y) age group, $63 \%$ of power loom male workers have shown abnormal pulmonary function test while $57 \%$ female workers were having shown abnormal PFT. In (40-60 y) age group, 75\% male workers have shown abnormal PFT while $70 \%$ female workers have shown abnormal PFT. The abnormal PFT percentage in male and female controls were less in both age groups. We compared BMI of powerloom workers with controls in both age groups. The linear regression analysis is $(0.292$; $95 \% \mathrm{CI}: 0.157-0.216) \mathrm{p}<0.05^{*}$.

\section{Hand grip meter (HGM) and muscle tone (MT)}

The HGM of the workers was as shown in table 2. In (20-40 y) age group, $55 \%$ of power loom male workers have shown abnormal hand grip meter while $54 \%$ female workers were having shown abnormal HGM. In (40-60 y) age group, 73\% male workers have shown abnormal HGM while $77 \%$ female workers have shown abnormal HGM. The abnormal HGM percentages in male and female controls were less in both age groups. We compared HGM of power loom workers with controls in both age groups. The linear regression analysis is $(0.351 ; 95 \% \mathrm{CI}: 0.257-0.266) \mathrm{p}<0.05^{*}$.

\section{Eyestrain and eyesight}

Apart from the effects of work on the body, the lungs, and muscle tone, repetitive work and the continuous visual attention to detail also appear to have an upset on the eyes of the workers. The ES of the workers was as shown in table 2. In (20-40 y) age group, $60 \%$ of power loom male workers have shown abnormal hand grip meter while 53\% female workers were having shown abnormal ES. In (4060 y) age group, $77 \%$ male workers have shown abnormal ES while $73 \%$ female workers have shown abnormal ES. The abnormal ES percentages in male and female controls were less in both age groups. We compared ES of power loom workers with controls in both age groups. The linear regression analysis is $(0.371 ; 95 \% \mathrm{CI}$ : $0.237-0.296) \mathrm{p}<0.05^{*}$. 


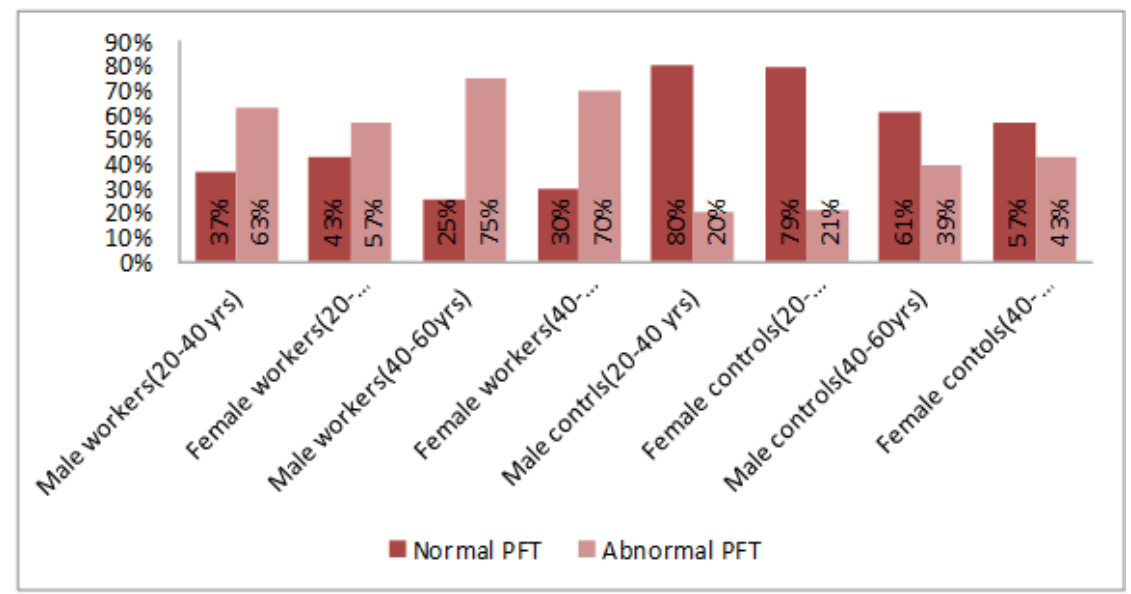

Fig. 2: Bar diagram showing percentage of pulmonary function test (PFT)

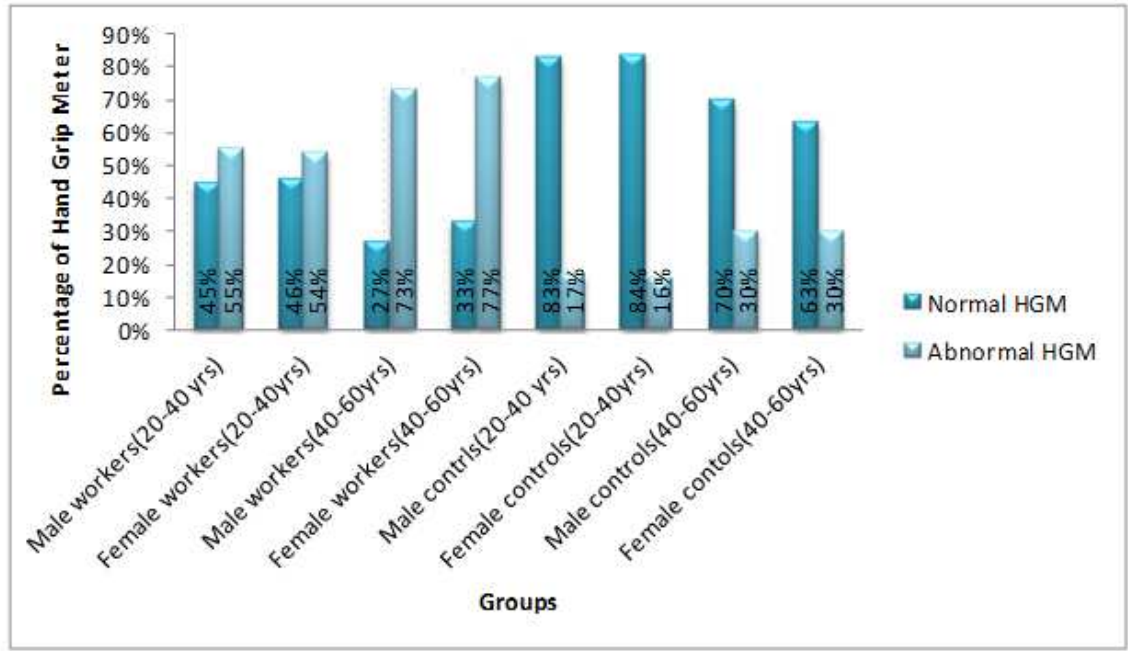

Fig. 3: Bar diagram showing percentage of a hand grip meter

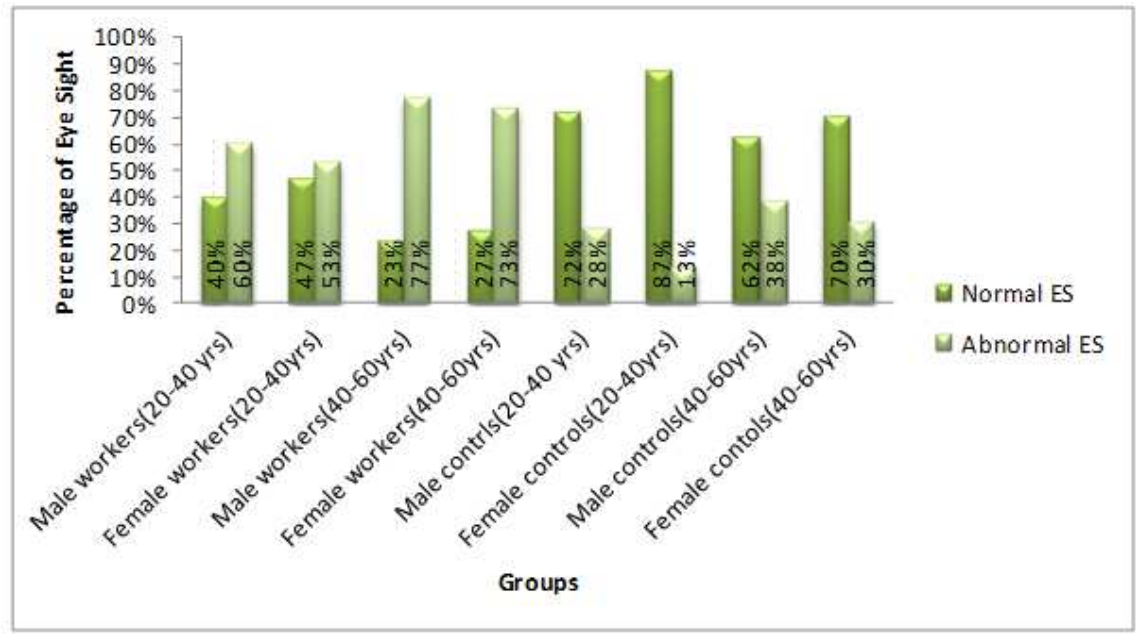

Fig. 4: Bar diagram showing percentage of eyesight

\section{CONCLUSION}

This study were covered the sample survey of 540 power loom workers in selected industries in Solapur city and the results were showed that most of the workers have been impacted by the unhealthy and non-safety working conditions which resulted in to $84.28 \%$ workers were affected by respiratory problems, $43.15 \%$ have reported an increase in muscle tone, $12 \%$ complained of eye problems and $73 \%$ have been found affected by musculoskeletal problem. Hence, there is an immediate need to reinforce their 
workplace safety and health policies and implement measures in accordance with the Indian Factories Act. This study was limited to Solapur city and we were assessed basic parameters to determine the health of the power-loom workers.

\section{AUTHOR CONTRIBUTION}

SK designed the study and prepared the manuscript. RH developed and analyzed the data. SK prepared the initial draft of the manuscript.

\section{CONFLICT OF INTERESTS}

All authors declare that there are no conflicts of interests

\section{REFERENCES}

1. Sahoo B. Problems and prospects of textile industry. New Delhi: Mittal Publications; 1993. p. 154.

2. Textile Commissioner. Handbook of Power-loom Industry. New Delhi: Ministry of Textiles, Govt. of India; 2006.

3. Textile Committee. A survey of various aspects of the powerloom sector of the textile industry in Maharashtra. Mumbai: Textile Committee, Govt. of India; 1996.

4. Shete S, Mali N, Kankur K, Phule S. Levels of socioeconomic development in solapur district-a geographical analysis. Int Res J 2009;2:542-5.

5. http://business.mapsofindia.com. [Last Accessed on $31 \mathrm{Mar}$ 2014]

6. http://midcindia.org. [Last Accessed on 31 Mar 2014]

7. Safety requirements for the textile industry: American National Standards Institute. The Institute, New York, standard No ANSI L1. 1-1972, 1972. Abstr. in World Textile Abstracts. Appl Erg 1973;4:222-3.

8. Suryakar A, Katkan R, Dhadke V, Bhogade R. A study of oxidative stress in cotton industry workers from Solapur city. Bio Res 2010;21:260-4.

9. Agnihotram R. An overview of occupational health research in India. Indian J Occup Environ Med 2005;9:10-4.
10. Knutsson A. Health disorders of shift workers. Occup Med 2003;53:103-8.

11. Metgud D, Khatri S, Mokashi M, Saha P. An ergonomic study of women workers in a woolen textile factory for identification of health-related problems. Indian J Occup Environ Med 2008;2:14-9.

12. Sant S, Ahsan A, Jaiswal K, Kumar S, Ang H, Singh A. A study on adverse effect of smoke/flue on lung functions of glass factory workers of Firozabad district. Indian J Com Health 2014;26:41-53.

13. Müezzino A. Air pollutant emission potentials of cotton textile manufacturing industry. J Clean Prod 1998;6:339-47.

14. Spiro T, Stigliani W. Chemistry for the environment: Upper Saddle River. New Jersey, Prentice Hall; 1996.

15. Hendrickson J, Cram D, Hammond G. Organic chemistry. New York, McGraw-Hill; 1995.

16. Gupta S, Malhotra V, Tripathi Y, Deva P. Respiratory functions in textile mill workers: role of peak expiratory flow rate. Asian J Pharm Clin Res 2017;10:306-8.

17. Ayesha Anjum, Ashfaq Ahmad Mann, M Aqeel Anjum. Health concerns among workers in weaving industry: a case study of tehsil faialabad, Pakistan. J Agric Soc Sci 2009;5:106-8.

18. Livingstone J, Ploof J. The Object of Labor: art, cloth, and cultural production. School of the Art Institute of Chicago Press; Cambridge, UK; 2007.

19. Duggal R, Dilip TR, Prashant R. Health and health care in maharashtra-a status report; 2005. http://hetv.org/pdf/ maharashtra/hhmbook.pdf. [Last Accessed on 31 Mar 2014]

20. Samiya A, Kelvin T, Alexandra C, Matthew C. Health and Safety in the Textile Dyeing Industry; 2007.

21. Hethorn J, Ulasewicz C. Sustainable fashion-why now?: A conversation exploring issues, practices, and possibilities. A and C Black Publishers Ltd, New York, USA; 2008.

22. M Anitha, Monica Roselin E, Monisha Dm, Chella Karthik J. Prevalence of obesity and overweight among medicos in both male and female students. Asian J Pharm Clin Res 2016;9:289-91. 